John D. Whi tcomb

STRAIN ENERGY RELEASE RATE ANALYSIS

OF CYCLIC DELAMINATION GROWTH IN COMPRESSIVELY LOADED LAMINATES 


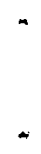

40

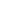




\title{
STRAIN ENERGY RELEASE RATE ANALYSIS OF CYCLIC DELAMINATION GROWTH IN COMPRESSIVELY LOADED LAMINATES
}

\author{
John D. Whitcomb \\ NASA Langley Research Center \\ Hampton, Virginia 23665
}

\section{SUMMARY}

Delamination growth in compressively loaded composite laminates was studied analytically and experimentally. The configuration used in the study was a laminate with an across-the-width delamination. An approximate superposition stress analysis was developed to quantify the effects of various geometric, material, and load parameters on mode I and mode II strain energy release rates $G_{I}$ and $G_{I I}$, respectively. Calculated values of $G_{I}$ and $G_{I I}$ were then compared with measured cyclic delamination growth rates to determine the relative importance of $G_{I}$ and $G_{I I}$. High growth rates were observed only when $G_{I}$ was large. However, slow growth was observed even when $G_{I}$ was negliglbly small. This growth apparently was due to a large value of $G_{I I}$.

\section{INTRODUCTION}

In composite structures subjected to compression loads, delaminations can cause localized buckling ( $f \mathrm{fg}$. 1). High interlaminar stresses at the edges of the buckled region often lead to cyclic delamination growth (herein referred to as instability-related delamination growth).

The objective of this paper is to investigate the mechanism of instabilityrelated delamination growth. Figure 1 shows the configuration used in the study--a laminate with a "through-width" delamination. This configuration was selected because it is perhaps the simplest configuration that exhibits instability-related delamination growth. Goals of the investigation were: (1) to develop and use an approximate superposition stress analysis to explain how various geometric, material, and load parameters affect interlaminar stresses, (2) to determine the delamination growth behaviors predicted by several different criteria based on strain energy release rates, and (3) to 
compare analytical calculations with experimental observations to determine the applicability of each growth criterion.

Because of the stress singularity at the end of the delamination (crack tip), calculated stresses there have little meaning. Strain energy release rates are finite parameters which characterize the intensity of the stresses near the crack tip. Consequently, in the following discussion strain-energy release rates will be used to characterize the severity of the interlaminar stresses.

\section{NOMENCLATURE}

a

$\overline{\mathbf{a}}$

$\Delta \mathbf{a}$

b

$\mathrm{C}, \mathrm{Cl}, \mathrm{C} 2, \mathrm{C} 3$, $\mathrm{n}, \mathrm{n} 1, \mathrm{n} 2, \mathrm{z}$

D

$d_{x}, d_{y}$

$\mathrm{E}^{\mathrm{k}}$

$E_{11}, E_{22}, E_{33}$ half-length of delamination before loading

half-length of delamination after loading

virtual crack closure distance used in strain energy

release rate calculations

specimen width

arbitrary constants

bending stiffness of the buckled region given by

$$
D=\frac{b}{3} \sum_{k=1}^{\rho} E^{k}\left[\left(\alpha_{k}-\frac{t}{2}\right)^{3}-\left(\alpha_{k-1}-\frac{t}{2}\right)^{3}\right]
$$

where $\rho=$ number of plies

unit load solutions for displacements near crack tip Young's modulus for ply $k$

Young's moduli of unidirectional ply. The subscripts 1 , 2 , and 3 refer to the longitudinal, transverse, and thickness directions respectively. 


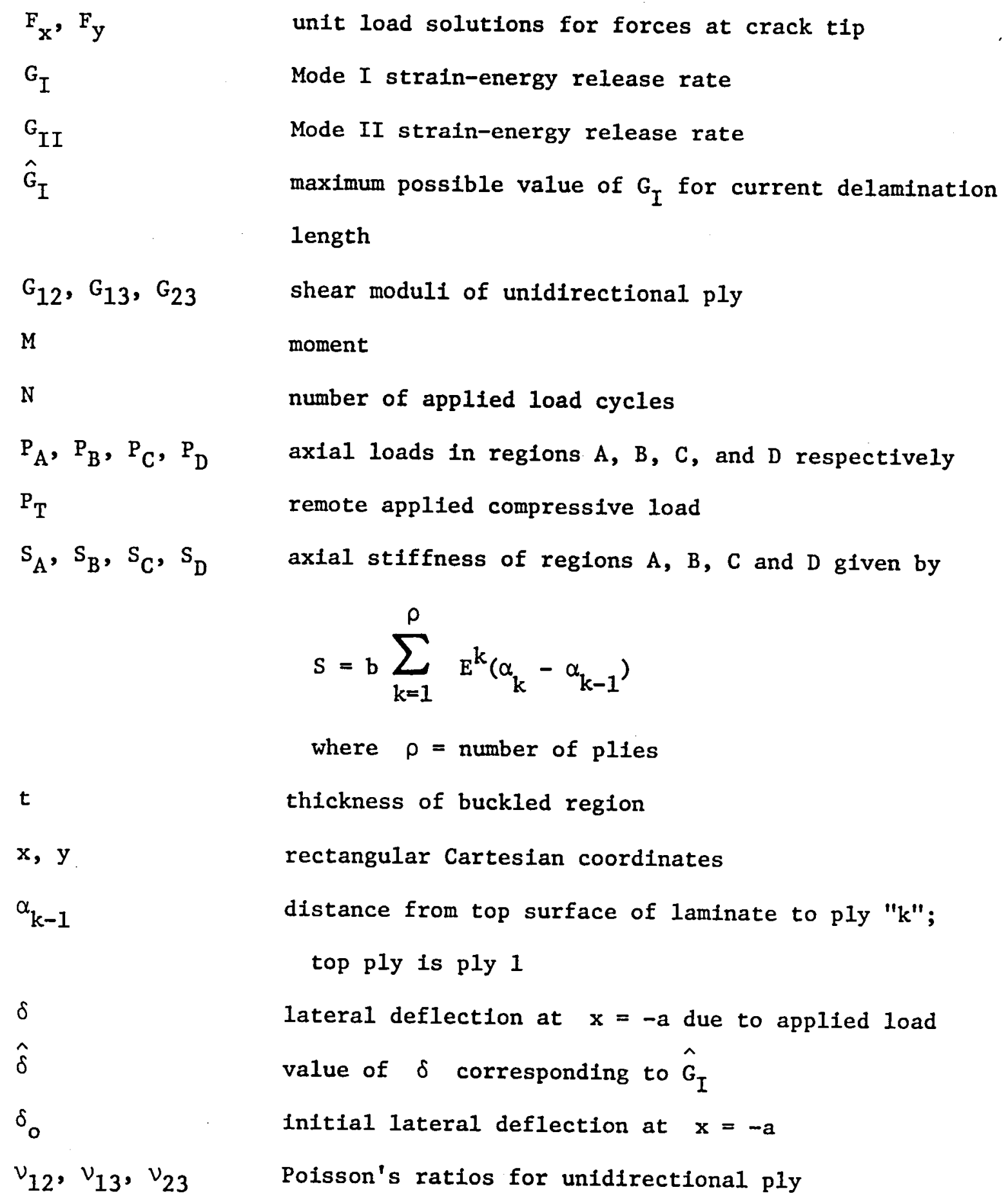




\section{ANALYSIS}

The configuration shown in figure 1 was idealized as a two dimensional plane strain problem. Linear and nonlinear finite element analyses and an approximate superposition analysis were used to calculate strain energy release rates for the two dimensional idealization. The nonlinear analysis was used to provide reference solutions for evaluation of the approximate superposition analysis. The linear analysis was used to calculate several constants used in the approximate superposition analysis. The nonlinear analysis is described in reference 2, and the linear analysis is simply a linear version of this analysis.

The approximate superposition analysis, the procedure for calculating strain energy release rates, the finite element models, and material properties are discussed in the following sections.

Approximate Superposition Analysis

Superposition techniques have been widely used in linear stress analysis to represent a complicated problem as a combination of several simpler problems. Application of the principle of superposition to nonlinear problems first requires a transformation that results in a linear system.

The key to the transformation is replacement of the source of nonlinearity with equivalent loads ( $f i g .2 a$ and $b$ ). Because of symmetry only half of the configuration is considered. The buckled region (which responds nonlinearly due to significant rotations) is replaced by the loads $P_{D}$ and $M$, the axial load and moment respectively in the column where it is cut (fig. 2b). The new configuration is linear, with three nonlinearly related applied loads $P_{T}, P_{D}$, and $M$. By superposition the number of loads can be reduced to two, as illustrated in figures $2 c-2 e$. 
The load system in figure $2 c$ is divided into the two load systems shown in figures $2 d$ and $2 e$. Because $P_{C}$ is calculated using rule of mixtures, the load system in figure $2 e$ causes a uniform axial strain state and no interlaminar stresses. Consequently, in terms of interlaminar stresses, only the load system in figure 2d (ie. $\left(P_{C}-P_{D}\right)$ and $M$ ) need be considered. Accordingly, in the current study involving strain energy release rates, figure $2 \mathrm{~d}$ is the linearized equivalent of the nonlinear problem in figure $2 a$.

The appendix describes a strength of materials analysis for calculating $\left(P_{C}-P_{D}\right)$ and $M$. The key equations from the appendix are

$$
\begin{gathered}
\mathrm{P}_{\mathrm{T}}=\frac{\pi^{2} \mathrm{~S}_{\mathrm{A}}}{\mathrm{a}^{2}}\left[\frac{\left(\delta^{2}+2 \delta \delta_{\mathrm{O}}\right)}{16}+\frac{\mathrm{D}\left(\mathrm{S}_{\mathrm{A}}+\mathrm{S}_{\mathrm{D}}\right)}{\mathrm{S}_{\mathrm{A}} \mathrm{S}_{\mathrm{D}}} \frac{\delta}{\delta+\delta_{\mathrm{O}}}\right] \\
\mathrm{P}_{\mathrm{C}}-\mathrm{P}_{\mathrm{D}}=\frac{\mathrm{S}_{\mathrm{D}}}{\mathrm{S}_{\mathrm{A}}+\mathrm{S}_{\mathrm{D}}} \mathrm{P}_{\mathrm{T}}-\frac{\pi^{2} \mathrm{D}}{\mathrm{a}^{2}} \frac{\delta}{\delta+\delta_{\mathrm{O}}} \\
M=\frac{\pi^{2} \mathrm{D}}{2 \mathrm{a}^{2}} \delta
\end{gathered}
$$

To use the loads $\left(P_{C}-P_{D}\right)$ and $M$ in a two dimensional analysis requires that they be expressed as an equivalent distribution of tractions. To calculate this distribution, the axial strains were assumed to vary linearly through the thickness where the tractions are applied (ie. at the cut). Intuitively, this seems to be reasonable if region $D$ (fig. 2) is not cut too close to the crack tip. The validity of the assumed linear variation will be checked later in this paper.

Linear finite element analysis was used to calculate the response of the linearized configuration in figure $2 d$ to unit values of $\left(P_{C}-P_{D}\right)$ and $M$. Because the configuration is linear, the solution for any arbitrary combination 
of $\left(P_{C}-P_{D}\right)$ and $M$ is simply a linear combination of the unit load responses. If region $B$ (fig. 2) is much thicker than region $C$, the unit load solutions are very insensitive to delamination length. In the current study the ratio of thicknesses was 61 to 3 . Hence, the unit load solutions for $2 \mathrm{a}=25 \mathrm{~mm}$ were used for analysing all delamination lengths. Also initial waviness of the buckled region does not enter into the finite element analysis. Delamination length and initial waviness were both accounted for in the strength of materials analysis in calculating $\left(P_{C}-P_{D}\right)$ and $M$, equations (2) and (3) respectively. This procedure will be discussed further in the next section.

\section{Strain Energy Release Rate}

The virtual crack closure method (ref. 1) was used to calculate mode I and mode II strain-energy release rates, $G_{I}$ and $G_{I I}$ respectively. The forces transmitted through the node at the crack tip and the relative displacements of the two nodes on the crack boundary closest to the crack tip were used in the calculation. Equations 4 show how this technique is used for the superposition stress analysis.

$$
\begin{aligned}
& G_{I}=\frac{1}{2 \Delta a b}\left[\left(P_{C}-P_{D}\right) F_{y}^{I}+M F_{y}^{2}\right]\left[\left(P_{C}-P_{D}\right) d_{y}^{1}+M d_{y}^{2}\right] \\
& G_{I I}=\frac{1}{2 \Delta a b}\left[\left(P_{C}-P_{D}\right) F_{x}^{1}+M F_{x}^{2}\right]\left[\left(P_{C}-P_{D}\right) d_{x}^{1}+M d_{x}^{2}\right]
\end{aligned}
$$

In these equations $F_{x}, F_{y}, d_{x}$, and $d_{y}$ are the unit load values of the nodal forces and the corresponding relative nodal displacements in the $x$ and $y$ directions. (The coordinate system is defined in fig. 2.) The superscripts 1 and 2 on the unit load parameters identify parameters associated with $\left(P_{C}-P_{D}\right)$ and $M$, respectively. 
If the distance is small between the crack tip and the nodes used to calculate relative displacements, then $F_{y}^{1} / d_{y}^{1}=F_{y}^{2} / d_{y}^{2}$ and $F_{x}^{1} / d_{x}^{1}=F_{x}^{2} / d_{x}^{2}$. Using these relationships in eqns. (4) results in

$$
\begin{aligned}
& G_{I}=\frac{1}{2 \Delta a b}-\frac{d_{y}^{1}}{F_{y}^{1}}\left[\left(P_{C}-P_{D}\right) F_{y}^{1}+M F_{y}^{2}\right]^{2} \\
& G_{I I}=\frac{1}{2 \Delta a b} \frac{d_{x}^{1}}{F_{x}^{I}}\left[\left(P_{C}-P_{D}\right) F_{x}^{1}+M F_{x}^{2}\right]^{2}
\end{aligned}
$$

In the results and discussion section it will be shown that for high loads or long delamination lengths, $G_{I}$ is zero, 1.e., the crack tip closes in the normal direction. To prevent the crack faces from overlapping (analytically) requires the addition of multipoint constraints on the crack face nodes. Conceptually, the crack face nodes are connected in the direction normal to the crack face by infinitesimal springs. These springs have infinite stiffness in compression and zero stiffness in tension. To determine whether to select zero or infinite stiffness requires solution of a nonlinear contact problem. To include the contact problem directly in the superposition analysis would severely complicate the otherwise simple equations. Therefore, use of a noncontact analysis to approximate $G_{I I}$ was Investigated.

A laminate with $2 a=76.2 \mathrm{~mm}$ was analyzed using two different approaches. First contact forces were ignored (i.e., overlap of crack faces was allowed). $G_{I}$ and $G_{I I}$ were calculated using equation (5). In the second approach, overlap of the crack faces was prevented, which is more realistic. $G_{\text {II }}$ was calculated using equation (5). (Note that eq. (5) yeilds $G_{I}=0$ when overlap is prevented.) Applied loads $\left(P_{T}\right)$ ranged from $14.8 \mathrm{kN}$, which corresponds approximately to Initial crack tip closure, to $55.2 \mathrm{kN}$. 
When crack face overlap was prevented, a larger value of $G_{I I}$ was calculated than when overlap was allowed. The difference in the $G_{I I}$ values increased with load. But in all cases the difference was approximately equal to $G_{I}$ calculated using the approach which allowed crack face overlap. For example, for $P_{T}=55.2 \mathrm{kN}$ the contact analysis yielded $G_{I I}=413 \mathrm{~J} / \mathrm{m}^{2}$. When crack face overlap was allowed, $G_{I}$ and $G_{I I}$ were 35 and $384 \mathrm{~J} / \mathrm{m}^{2}$, respectively. The sum of these values is within approximately 1.5 percent of the more realistic solution, 1.e., $G_{I I}=413 \mathrm{~J} / \mathrm{m}^{2}$. Apparently the crack-face contact forces do not significantly alter the total strain energy release rate. Hence, when there is crack tip closure, the total strain energy release rate from the non-contact analysis can be used to approximate $G_{I I}$ (which is then the total strain energy release rate, since $G_{I}$ is identically zero).

Finite Element Model

A typical finite element mesh for the nonlinear analysis is shown in figure 3. Because of symmetry only half of the laminate was modeled. The mesh contains 813 nodes and 740 four-node isoparametric elements. Reduced integration was used to improve the performance of the elements in modeling bending deformations. Because the rotations are small except in part of the buckled region, the nonlinear strain-displacement relations were used only for the region $y>0,-a \leq x \leq-0.56 \mathrm{~mm}$. As shown in figure $2(\mathrm{~b})$, the linearized configuration is the same as the nonlinear configuration except that most of the buckled region is removed. Accordingly, the mesh used in the linear analysis was derived from that in figure 3 by removing elements in the deleted part of the buckled region. 


\section{Materials Properties}

The material studied was NARMCO T300/5208* graphite/epoxy. The unidirectional ply properties were assumed to be

$$
\begin{aligned}
& E_{11}=140 \mathrm{GPa} \\
& E_{22}=E_{33}=14 \mathrm{GPa} \\
& \nu_{12}=v_{13}=\nu_{23}=0.21 \\
& G_{12}=G_{13}=G_{23}=5.9 \mathrm{GPa}
\end{aligned}
$$

Plane strain (1.e., $\varepsilon_{z}=0$ ) and $\varepsilon_{x z}=0$ were imposed to calculate the 2D properties. In regions where coarse fintte elements spanned several plies, laminate theory was used to obtain average properties.

*Use of trade names or manufacturers does not constitute an official endorsement, either expressed or implied, by the National Aeronautics and Space Administration. 


\section{EXPERIMENTAL PROCEDURE}

The specimens used for this study were fabricated and tested by Northrop Corporation. (Details will appear in NASA CR-166046, "Performance of a Quantitative Study of Instability-Related Delamination Growth," by R. L. Ramkumar.) A cursory description of the experimental procedure is given herein.

The specimen consisted of 64 plies of T300/5208. The fiber orientation and stacking sequence were $\left[0_{4} /(0 / 45 / 90 /-45){ }_{7}\right]_{s}$. The laminate width, $b$, was $25.4 \mathrm{~mm}$ To simulate a delamination, kapton film was used to prevent bonding over a 19 length between the third and fourth plies. The ply thickness was assumed to be $0.14 \mathrm{~mm}$. Six specimens were tested in fatigue under compressive constant-amplitude loads. Minimum compressive load was ten percent of the maximum compressive load. The load frequency was $10 \mathrm{~Hz}$. Delamination lengths were measured with a microscope.

\section{RESULTS AND DISCUSSION}

First, the accuracy of the approximate superposition analysis will be evaluated. Then the effect of various parameters on $G_{I}$ and $G_{I I}$ will be considered. Finally, the experimental observations will be compared with the analytical results.

Evaluation of Approximate Superposition Analysis

The approximate superposition analysis was evaluated by comparison with results from a geometrically nonlinear finite element analysis. Recall that a major assumption in the approximate analysis was that the strains vary linearly through the thickness where $\left(P_{C}-P_{D}\right)$ and $M$ are applied. Fig. 4 shows the axial strain variation through the thickness at $x=-0.2$ and $-0.7 \mathrm{~mm}$ obtained using the nonlinear finite element analysis. Along the line $x=-0.7 \mathrm{~mm}$ the strains vary almost linearly for the three applied loads. However, closer to the crack tip along $x=-0.2 \mathrm{~mm}$ the varlation is more nonlinear, espectally 
near $y=0$. In the following, $\left(P_{C}-P_{D}\right)$ and $M$ were applied at $\mathrm{x}=-0.76 \mathrm{~mm}$.

The unit load solutions $F_{x}, F_{y}, d_{x}$, and $d_{y}$ are

$$
\begin{aligned}
& F_{x}^{1}=9.36 \times 10^{-5} \\
& F_{x}^{2}=0.531 \mathrm{~m}^{-1} \\
& F_{y}^{1}=0.0261 \\
& F_{y}^{2}=-0.252 \mathrm{~m}^{-1} \\
& d_{x}^{1}=1.40 \times 10^{-10} \mathrm{~m}-\mathrm{N}^{-1} \\
& d_{y}^{1}=1.17 \times 10^{-8} \mathrm{~N}^{-1}
\end{aligned}
$$

These values were used in equation 5 for any combination of $\left(P_{C}-P_{D}\right)$ and $M$ to obtain $G_{I}$ and $G_{I I}$.

Differences between $G_{I}$ and $G_{I I}$ from the approximate superposition analysis and the geometrically nonlinear finite element analysis can be traced mainly to two sources: (I) nonlinear variation of the strains through the thickness of the buckled region and (2) inaccuracy in determining $\left(P_{C}-P_{D}\right)$ and $M$.

By using $\left(P_{C}-P_{D}\right)$ and $M$ from the geometrically nonlinear finite element analysis, the effect of nonlinear variation of the strains can be examined. Figure 5 shows that this effect is small.

Figure 6 shows that if the strength of materials analysis is used to calculate $\left(P_{C}-P_{D}\right)$ and $M$, the difference is much larger. Hence, most of the difference between the two analyses is due to inaccuracy in determining $\left(P_{C}-P_{D}\right)$ and $M$. But the general trends for the $G_{I}$ variation with delamination length and load are predicted very well. In figure 6 the curves for the two analyses seem to differ (approximately) by a constant scale factor. 
A direct test of the approximate analysis for predicting trends is to use it to coalesce the curves in figure 6 into a single curve. Equations (2) and (3) show that $\left(P_{C}-P_{D}\right)$ and $M$ can be expressed as functions of $\delta$. Hence, from equations (5), $G_{I}$ and $G_{I I}$ are functions of $\delta$. Equations (1), (2), (3), and (5) show that for constant $\delta, P_{T}$ varies as $a^{-2}$ and $G_{I}$ and $G_{I I}$ vary as $a^{-4}$. Hence, plotting $a^{4} G_{I}$ vs $a^{2} P_{T}$ should coalesce the curves for various delamination lengths. Figure 7 shows that the data for five delamination lengths (including those in fig. 6) do coalesce into a narrow band around a single curve. Since the peak values of $G_{I}$ for various lengths differ by more than two orders of magnitude, the closeness of the fit suggests the approximate analysis is accurate for predicting trends. Therefore, all results that follow are obtained with the approximate superposition analysis. Figure 7 also shows that if nonlinear finite element results are available for one delamination length, the values for other lengths can be estimated immediately.

An advantage of the superposition analysis is that it allows a problem to be dissected. In particular, one can determine the relative importance of the loads $\left(P_{C}-P_{D}\right)$ and $M$ on $G_{I}$ and $G_{I I}$. Figures 8 and 9 show $G_{I}$ and $G_{I I}$ calculated by using $M$ alone and by using $\left(P_{C}-P_{D}\right)$ and $M$ in combination. Although intuition might suggest that only the peeling action caused by the moment $M$ has a significant effect on $G_{I}$, figure 8 shows that $\left(P_{C}-P_{D}\right)$ contributions cannot be ignored. Figure 9 shows that both $\left(P_{C}-P_{D}\right)$ and $M$ are also important when calculating $G_{I I}$.

Parametric Study

The effects of several parameters on $G_{I}$ and $G_{I I}$ were examined using the approximate superposition analysis. The parameters were initial waviness, 
delamination length, applied 1oad, and the ratio of axial to bending stiffness for the buckled region.

Inftial imperfections in the form of simple sinusoidal waviness were assumed (eq. (6))

$$
\left.\mathrm{v}(\mathrm{x})\right|_{\text {INITIAL }}=\frac{\delta_{0}}{2}\left(1-\cos \frac{\pi \mathrm{x}}{\mathrm{a}}\right)
$$

where $v(x)=$ Distortion in the $y$ direction. When a column is initially wavy, bifurcation buckling does not occur. As soon as load is applied, the column begins to deflect laterally, which causes interlaminar stresses. Hence, $G_{I}$ and $G_{I I}$ are nonzero as soon as load is applied. If $\delta_{0}=0, G_{I}$ and $G_{I I}$ are zero until buckling occurs. However, figure 10 shows that the peak value of $G_{I}$ is significantly reduced, even for very small imperfections. In contrast, figure 11 shows that $G_{I I}$ is hardly affected by initial waviness.

Figures 6, 12, and 13 show the effect of delamination length on $G_{I}$ and $G_{I I}$. The shorter delaminations have the larger values of peak $G_{I}$ (i.e., $\hat{G}_{I}$ ) (fig. 6). However, for the longer delaminations $G_{I}$ becomes nonzero at lower loads. Figure 12 shows that after only a little delamination growth, $G_{I}$ reaches a peak and decreases rapidly with further growth. At $2 a=40-50 \mathrm{~mm}$, the crack tip closes in the normal direction and $G_{I}$ is identically zero. Further delamination growth causes compressive normal stresses to develop at the crack tip. In contrast, $G_{\text {II }}$ initially increases then decreases only slightly to a constant value with increased delamination length (fig. 13). Note that $G_{I I}$ is typically much larger than $G_{I}$.

Figures 6 and 14 illustrate the effects of applied load on $G_{I}$ and $G_{I I}$, respectively. The mode $I$ strain energy release rate $G_{I}$ first increases to a peak value $\left(\hat{G}_{I}\right)$, then decreases with increasing load (fig. 6). In contrast, $G_{\text {II }}$ monotonically increases with increasing load. As a result, $G_{I}$ and $G_{I I}$ do not usually reach peak values 
at the same time during a fatigue load cycle. Furthermore, the load at which $G_{I}$ is maximum decreases with increasing delamination length.

Since $\hat{G}_{I}$ is the maximum possible value of $G_{I}$ for a given delamination length, it is of interest how $\hat{G}_{I}$ varies with delamination length. The first step in determining this variation is to determine the lateral deflection $\hat{\delta}$ corresponding to $\hat{G}_{\mathrm{I}}$. The lateral deflection $\hat{\delta}$ is obtained by solving

$$
\frac{\partial G_{I}}{\partial \delta}=0
$$

Equations (2), (3), (5), and (7) are combined to obtain the governing equation (eq. (8))

$$
\mathrm{d}_{\mathrm{y}}^{1}\left[\frac{\mathrm{s}_{\mathrm{A}} \mathrm{s}_{\mathrm{D}}}{\mathrm{s}_{\mathrm{A}}+\mathrm{s}_{\mathrm{D}}} \frac{\hat{\delta}\left(1+\delta_{\mathrm{o}}\right)}{8}+\frac{\mathrm{D} \delta_{\mathrm{o}}}{\left(\hat{\delta}+\delta_{\mathrm{o}}\right)^{2}} \frac{1-\mathrm{s}_{\mathrm{A}}}{\mathrm{s}_{\mathrm{A}}}\right]+\frac{\mathrm{d}_{\mathrm{y}}^{2}}{2}=0
$$

Equation (8) is solved iteratively for $\hat{\delta}$. Once $\hat{\delta}$ is determined, $\hat{G}_{I}$ can be calculated from equation (1), (2), (3), and (5). Note that $\hat{\delta}$ is independent of delamination length. Earlier it was shown that for constant $\delta, G_{I}$ and $G_{I I}$ vary as $a^{-4}$ and $P_{T}$ varies as $a^{-2}$. Hence, $\hat{G}_{I}$ varies as $a^{-4}$ and the corresponding applied load varies as $a^{-2}$. The corresponding value of $G_{I I}$ also varies as $a^{-4}$. These observations will be of special interest later when examining the fatigue data.

The last parameter to be examined is the ratio of flexural-to-axial stiffness (i.e., D/S ) of the delaminated region. The buckling load for the region is linearly related to D. Prior to buckling, the load in the delaminated region is linearly related to $S_{D}$. Hence, for thick specimens with a thin delaminated region the applied load which causes buckling depends on the ratio $D / S_{D}$. Delaminated regions are less prone to buckle if they possess low 
axial stiffness and high flexural stiffness. But for homogeneous materials or unidirectional orthotropic laminates, this ratio is simply

$$
\frac{D}{S_{D}}=\frac{t^{2}}{12}
$$

Hence, the applied load which causes buckling is independent of the material properties of the buckled region. However, for multi-directional laminates the ratio $\mathrm{D} / \mathrm{S}_{\mathrm{D}}$ depends on both the lamina properties and the stacking sequence. For example, the value of $S_{D}$ for a $\left[\mathrm{O}_{3}\right]$ laminates is approximately 1.4 times that for a $[0 / 90 / 0]$ laminate, but the value of $\mathrm{D}$ is essentially the same for both laminates. Consequently, for a thick laminate with a delamination, buckling occurs at a lower applied load if the delaminated region is $\left[0_{3}\right]$ rather than $[0 / 90 / 0]$.

Comparison of Analysis and Fatigue Data

The roles of $G_{I}$ and $G_{I I}$ in delamination growth were investigated by comparing calculated values of $G_{I}$ and $G_{I I}$ with measured growth rates. Fatigue data for six specimens from reference 3 were used for comparison with analytical results. Three of the specimens were tested at $\left(\mathrm{P}_{\mathrm{T}}\right)_{\max }=33 \mathrm{KN}$ and another three at $\left(\mathrm{P}_{\mathrm{T}}\right)_{\max }=30 \mathrm{KN}$. The results are presented in figure 15. $\frac{\mathrm{da}}{\mathrm{dN}}$ decreased rapidly with delamination growth. Both curves are approximately linear with a slope of -4 , hence

$$
\frac{\mathrm{da}}{\mathrm{dN}} \approx \mathrm{Ca}^{-4}
$$

Figure 16 shows $\frac{\mathrm{da}}{\mathrm{dN}}$ vs. the maximum values of $G_{I}$ and $G_{I I}$ during fatigue cycling at a maximum compressive load of $33 \mathrm{kN}$. Note that the growth rate is largest when $G_{I}$ is relatively large. But slow growth is observed 
even when $G_{I}$ is very small. The mode II strain energy release rate $G_{\text {II }}$ changes little after initial delamination growth. Since $G_{I I}$ remains large, delamination growth likely is driven by $G_{I I}$.

Two delamination growth criteria were examined to determine whether they could predict the observed growth rates. The first growth criterion examined is given by

$$
\frac{\mathrm{da}}{\mathrm{dN}}=Z G_{I}^{\mathrm{n}}
$$

where $Z$ and $n$ are constants. Eqn. (11) is evaluated at the point in the load cycle when $G_{I}$ is maximum. The load range and delamination lengths are such that for almost the entire test, the maximum $G_{I}$ during each load cycle is $\hat{G}_{I}$, which was obtained by solving equation (7). Recognizing that $\hat{G}_{I}$ decreases as $a^{-4}$, as shown earlier, equations (10) and (11) can be solved for $\mathrm{n}$; the result is $\mathrm{n}=1$. This is in strong contrast to published values of $\mathrm{n} \approx 15-20$ for double cantilever beam fatigue tests (ref. 3). Apparently, equation (11) is not a valid growth criterion for the specimens considered. Next a growth criterion was considered which includes both $G_{I}$ and $G_{I I}$. If we assume there is no synergistic interaction of $G_{I}$ and $G_{I I}$ (i.e., the effects are separable), then

$$
\frac{d a}{d N}=f_{1}\left(G_{1}\right)+f_{2}\left(G_{I I}\right)
$$

where $f_{1}$ and $f_{2}$ are functions of $G_{I}$ and $G_{I I}$ respectively.

From the double cantilever beam data just discussed, we know that $f_{1}$ is extremely sensitive to $G_{I}$ (i.e., $\left.\frac{\mathrm{da}}{\mathrm{dN}} \propto \mathrm{G}_{I}^{15}\right)$. Since $\mathrm{G}_{I}$ decreases rapidly with increasing " $a$ ", $f_{1}$ must also decrease extremely fast as "a" increases. In fact, $f_{1}$ would not contribute noticeably to $\mathrm{da} / \mathrm{dN}$ after 
the inftial growth. Hence delamination growth appears to be driven by $G$ II alone. Accordingly, it was assumed that the growth criterion should be evaluated when $G_{I I}$ is maximum, 1.e., at peak load. However, earlier it was shown that for long delaminations the crack tip closes and produces compressive $\sigma_{y}$ stresses when the cyclic load is maximum. The compressive stress probably reduces the effect of $G_{\text {II }}$ on delamination growth, but it was not clear how to account for this stress. Two approaches were tried: (1) Ignore the compressive normal stress and set $f_{1}=0$ when the tip closes or (2) let $f_{1}$ take on negative values after the crack tip closes. If we choose to set $f_{1}=0$ when the crack tip closes, then

$$
\frac{d a}{d N}=f_{2}\left(G_{I I}\right)
$$

for virtually the entire test. Figure 14 showed that $G_{\text {II }}$ first increased then decreased slightly as the delamination extends. In the experiments two load levels were used: $\left(P_{T}\right)_{\max }=33 \mathrm{KN}$ and $30 \mathrm{KN}$. Figure 14 shows that for $2 a>25 \mathrm{~mm}$, the minimum value of $G_{I I}$ for $\left(\mathrm{P}_{\mathrm{T}}\right)_{\max }=33 \mathrm{kN}$ is greater than the maximum value of $G_{I I}$ for $\left(P_{T}\right)_{\max }=30 \mathrm{kN}$. Hence, equation (13) would predict that for $2 a>25 \mathrm{~mm}$, the minimum $\mathrm{da} / \mathrm{dN}$ for the higher load should exceed the maximum $\mathrm{da} / \mathrm{dN}$ at the lower load. Figure 16 shows this is not the case. Hence, equation (13) is not valid.

If we select a function $f_{I}$ that becomes negative when the crack tip closes, then we (analytically) allow compressive normal stresses at the crack tip to retard delamination growth due to $G_{I I}$. Since the compressive crack tip stresses increase as the delamination grows, such a function $f_{1}$ would predict a decrease in growth rate with increased delamination length. Although this prediction agrees with the data trend in figure 15, more tests are needed to verify or disprove this interpretation. 
Despite the complexity of the growth behavior, two trends were clear: (1) high growth rates were observed only when $G_{I}$ was large, and (2) slow growth was observed even when $G_{I}$ was negligibly small; apparently, $G_{I I}$ alone can drive delamination growth.

\section{CONCLUSIONS}

Analysis and experiments were used to study instability-related delamination growth in a fatigue specimen with a through-width delamination. To perform the analysis an approximate superposition analysis was developed. The analysis expresses $G_{I}$ and $G_{I I}$ in closed form, which can be used easily to determine the effects of various parameters. The analysis agreed very well with more rigorous solutions.

The response of the delaminated laminate to applied loads was found to be very complex. Key observations are listed below.

(1) $G_{\text {II }}$ is generally much larger than $G_{I}$.

(2) $G_{I}$ and $G_{I I}$ usually reach their peak magnitudes at different points in a fatigue cycle. $G_{\text {II }}$ always reaches its peak value at maximum load.

(3) High delamination growth rates were accompanied by large values of $\mathrm{G}_{\mathrm{I}}$.

(4) Slow growth rates were observed even when $G_{I}$ was negligibly sma11. This growth apparently was due to a large value of $G_{I I}$. 


\section{APPENDIX}

A strength of materials analysis is described herein for the configuration in figure 1.

The configuration is subdivided into four regions, as shown in figure 2. Because of symmetry, only half of the laminate is modeled. The laminate is of width b. The following assumptions are made:

1. Regions $B$ and $C$ are perfectly bonded. Regions $A$ and $D$ are unbonded.

2. Regions $A, B$, and $C$ have constant axial strain. Hence, the forcedisplacement relations are those for a simple rod subjected to axial load.

3. Region $D$ has zero slope at both ends.

4. Region $D$ has an initial sinusoidal imperfection of peak magnitude $\delta_{0}$. The initial shape is given by

$$
\left.v(x)\right|_{\text {initial }}=\frac{\delta_{0}}{2} \cdot\left(1-\cos \frac{\pi x}{a}\right)
$$

where $v(x)=$ the distortion in the $y$ direction.

To describe the nonlinear behavior of region $D$, equations (A2) and (A3) for post-buckling of a column were used.

$$
\begin{aligned}
& P_{D}=\frac{\pi^{2} D}{a^{2}} \frac{\delta}{\delta+\delta_{0}} \\
& a-\bar{a}=\frac{\pi^{2}}{16 a}\left(\delta^{2}+2 \delta \delta_{0}\right)+\frac{a P_{D}}{S_{D}}
\end{aligned}
$$

where $\delta, a, \bar{a}$, and $P_{D}$ are peak lateral deflection, axial length before and after deformation, and load, respectively. Equations (A2) and (A3) were derived.using strength of materials analysis of a column. 
To combine regions $A, B, C$, and $D$, equilibrium and compatibility conditions must be considered. The equilibrium condition for the axial force is

$$
\mathrm{P}_{\mathrm{A}}+\mathrm{P}_{\mathrm{D}}=\mathrm{P}_{\mathrm{B}}+\mathrm{P}_{\mathrm{C}}=\mathrm{P}_{\mathrm{T}}
$$

Compatibility requires the shortening of regions $A$ and $D$ to be identical. Hence,

$$
\frac{P_{A} a}{S_{A}}=a-\bar{a}
$$

Equations (A2) to (A5) can be combined to obtain the governing equation for the laminate.

$$
P_{T}=\frac{\pi^{2} S_{A}}{a^{2}}\left[\frac{1}{16}\left(\delta^{2}+2 \delta \delta_{0}\right)+\frac{D\left(S_{A}+S_{D}\right)}{S_{A} S_{D}} \frac{\delta}{\delta+\delta_{0}}\right]
$$

For a specified load $P_{T}$, equation (A6) is solved using a Newton-Raphson technique to obtain $\delta . P_{D}$ can then be calculated using equation (A2). From static equilibrium, the moment acting on the delaminated region at the crack tip is

$$
M=\frac{P_{D}}{2}\left(\delta+\delta_{0}\right)=\frac{\pi^{2} D}{2 a^{2}} \delta
$$

The force $\mathrm{P}_{\mathrm{C}}$ is found from rule of mixtures as

$$
P_{C}=\frac{S_{D}}{S_{A}+S_{D}} \quad P_{T}
$$




\section{REFERENCES}

[1] Rybicki, E. F.; and Kanninen, M. F.: A Finite Element Calculation of Stress Intensity Factors by a Modifled Crack Closure Integral. EngineerIng Fracture Mechanics, vo1. 9, no. 4, 1977, pp. 931-938.

[2] Whitcomb, J. D.: Finfte Element Analysis of Instability-Related Delamination Growth. Journal of Composite Materials, vol. 15, Sept. 1981,
pp. 403-426.

[3] Wilkins, D. J.: A Comparison of the Delamination and Environmental Resistance of a Graphite-Epoxy and a Graphite-Bismaleimide. Naval Air Systems Command Report NAV-GD-0037, 1981.

[4] Brush, D. 0.; and Almroth, B. L.: Buckling of Bars, Plates, and Shells. McGraw-Hi11 Book Co., Inc., New York, 1975, pp. 13-14.

[5] Ashizawa, M.: Fast Interlaminar Fracture of a Compressively Loaded Composite Containing a Defect. Presented at the Fifth DOD/NASA Conference on Fibrous Composites in Structural Design, New Orleans, LA, Jan. 1981.
(Douglas Paper No. 6994.). 


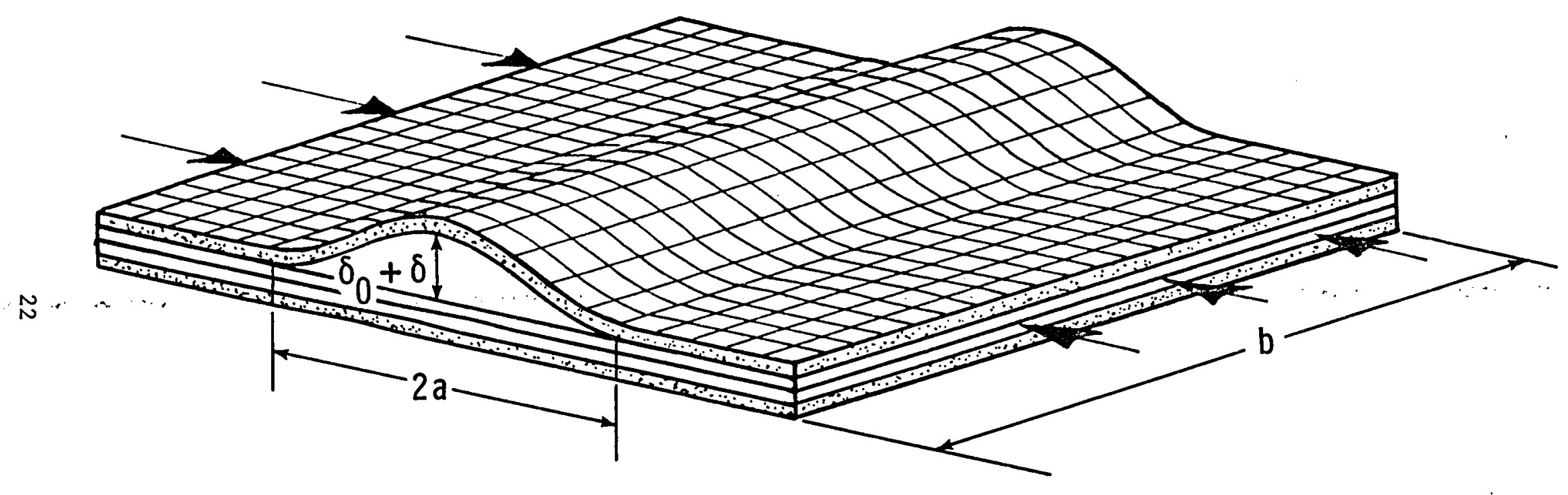

Fig. 1- Local buckling of laminate with through-width delamination. 


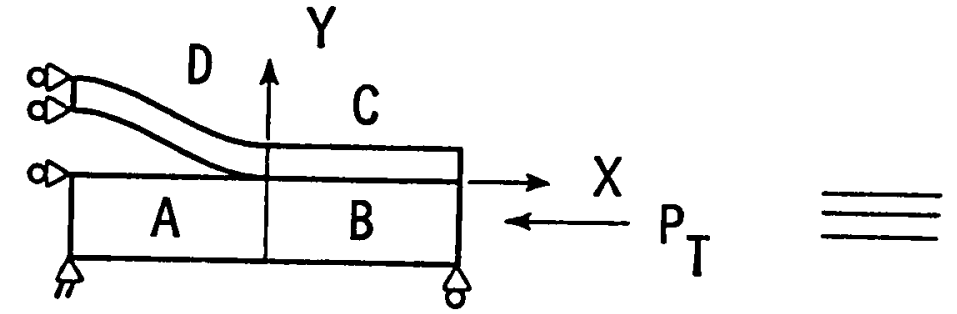

(a)

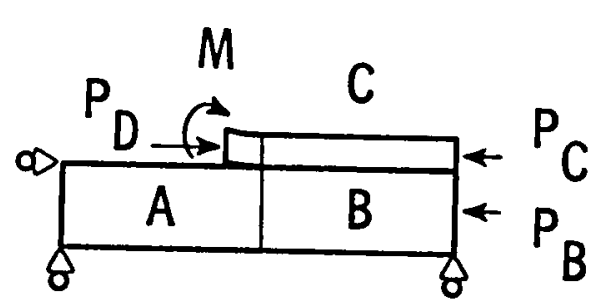

(b)

$\stackrel{\sim}{\omega}$

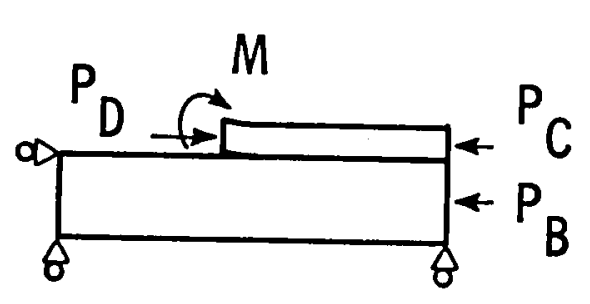

(c)

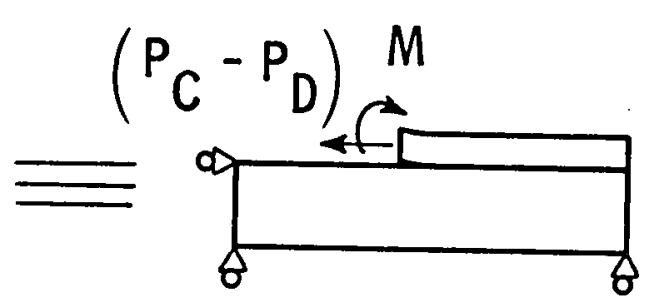

(d)

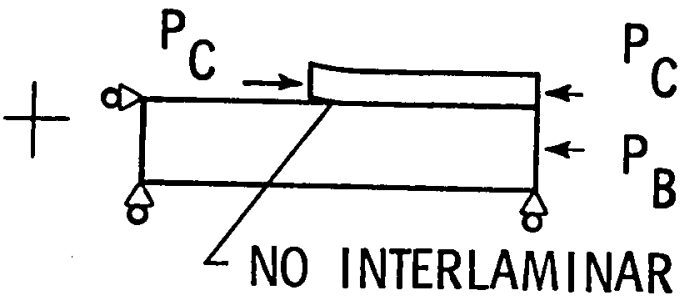

(e)

Fig. 2- Nonlinear configuration (a) transformed into linear configuration (d) with two nonlinearly related loads, $\left(\mathrm{P}_{\mathrm{C}}-\mathrm{P}_{\mathrm{D}}\right)$ and $\mathrm{M}$. 


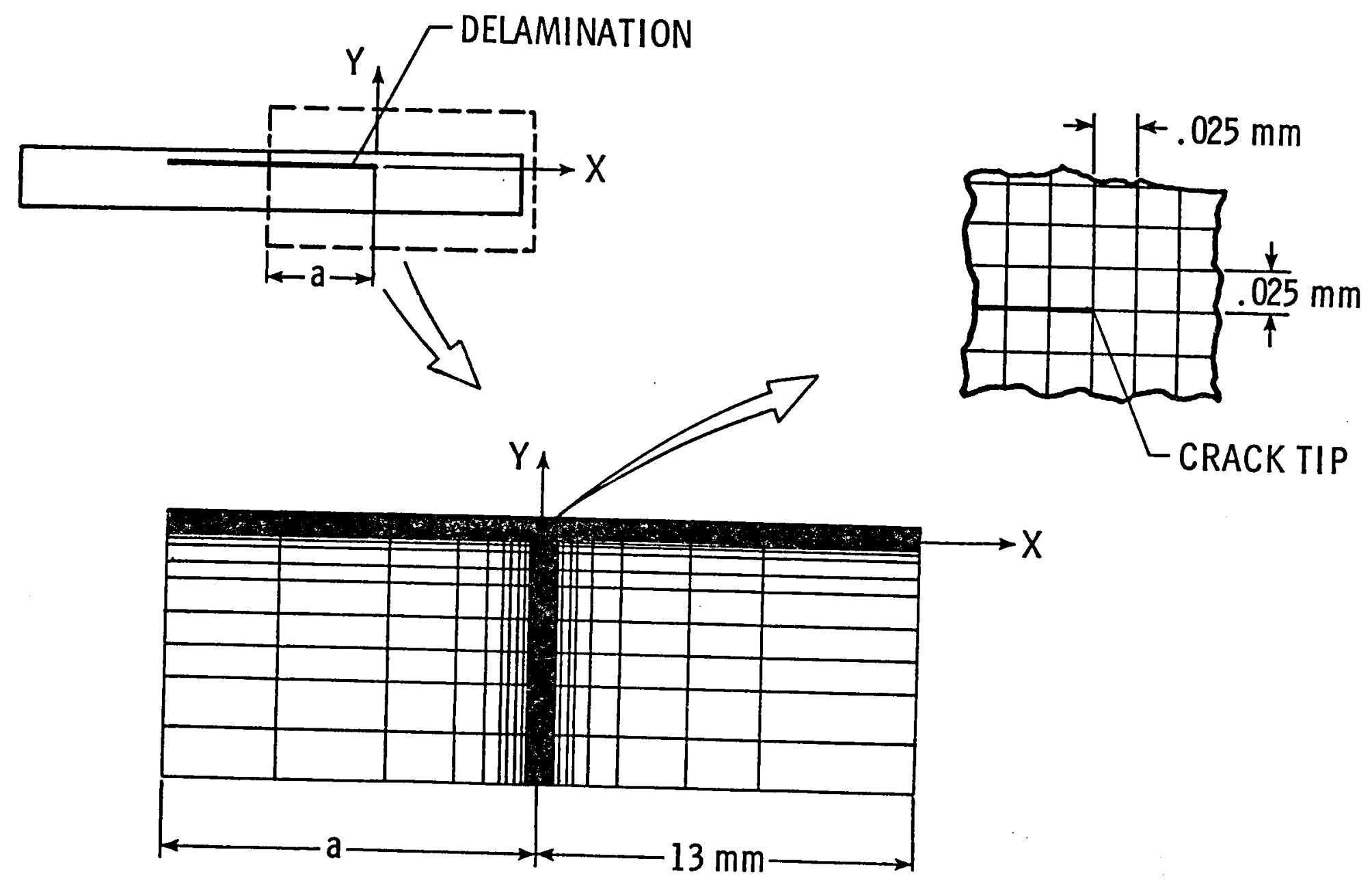

Fig. 3- Typical finite element mesh. 


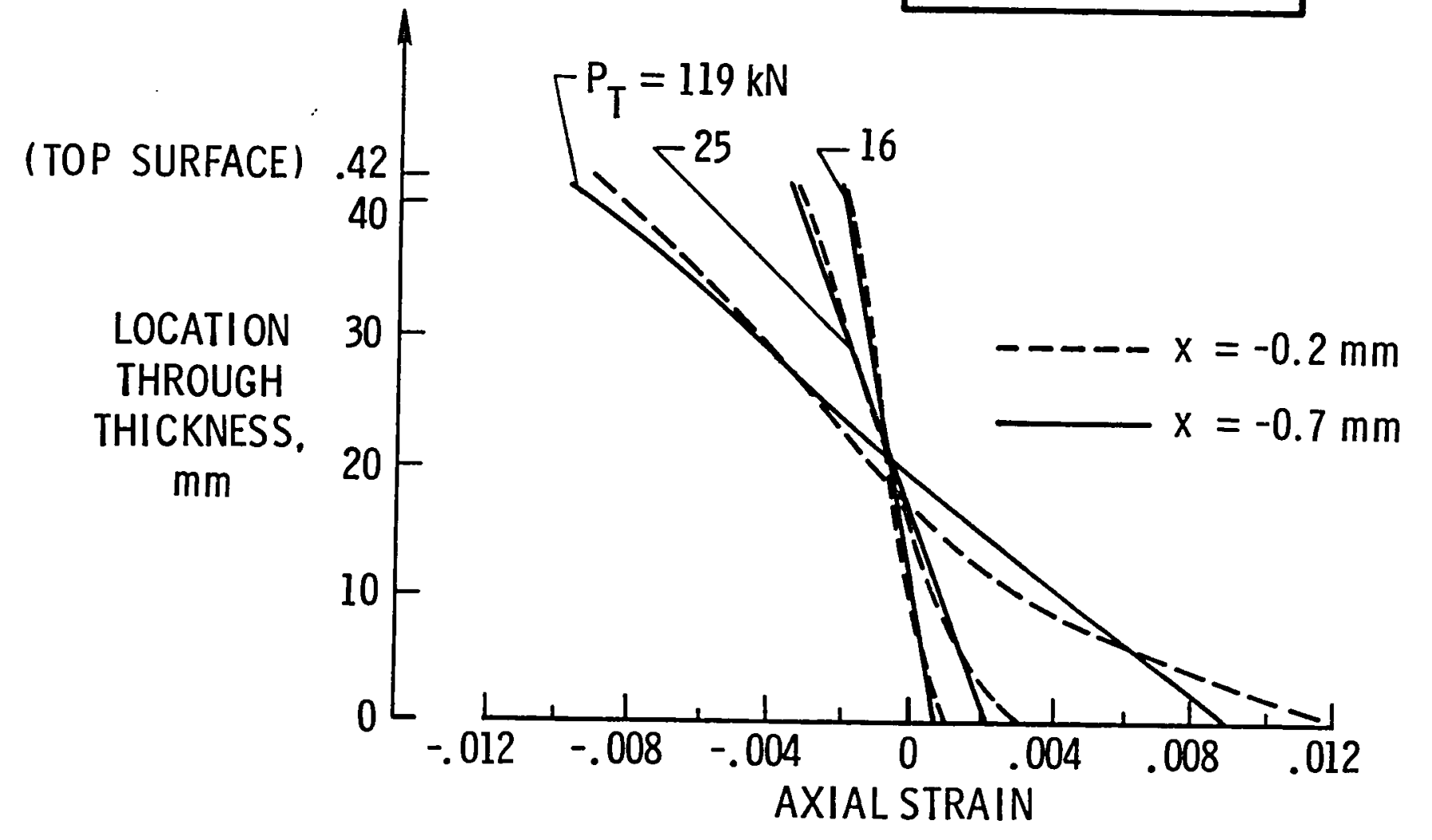

Fig. 4- Variation of axial strain through thickness of buckled region $(2 a=25 \mathrm{~mm})$, nonlinear analysis. 


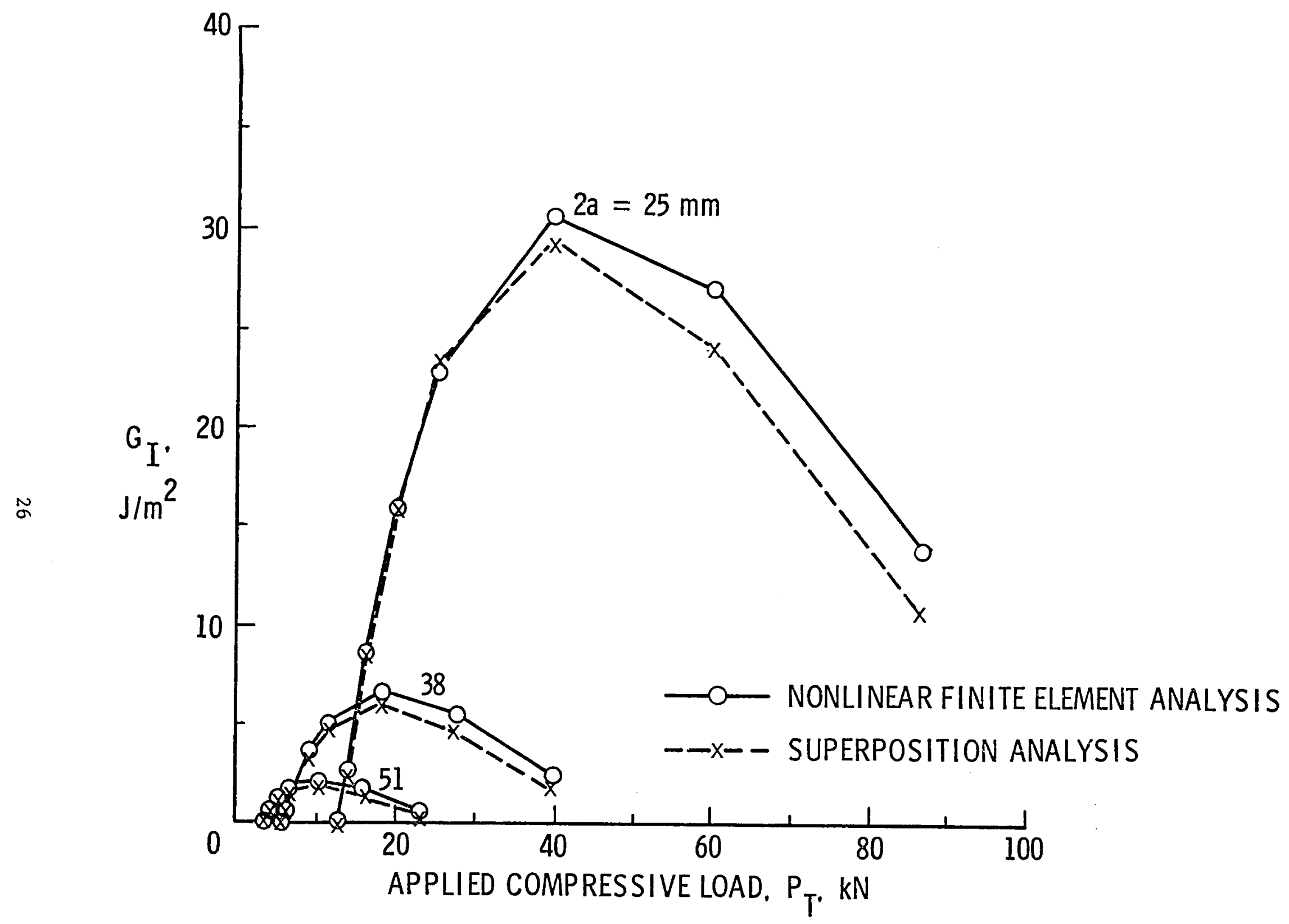

Fig. 5- Evaluation of approximate superposition analysis $\left(\left(P_{C}-P_{D}\right)\right.$ and $M$ from nonlinear finite element analysis). 


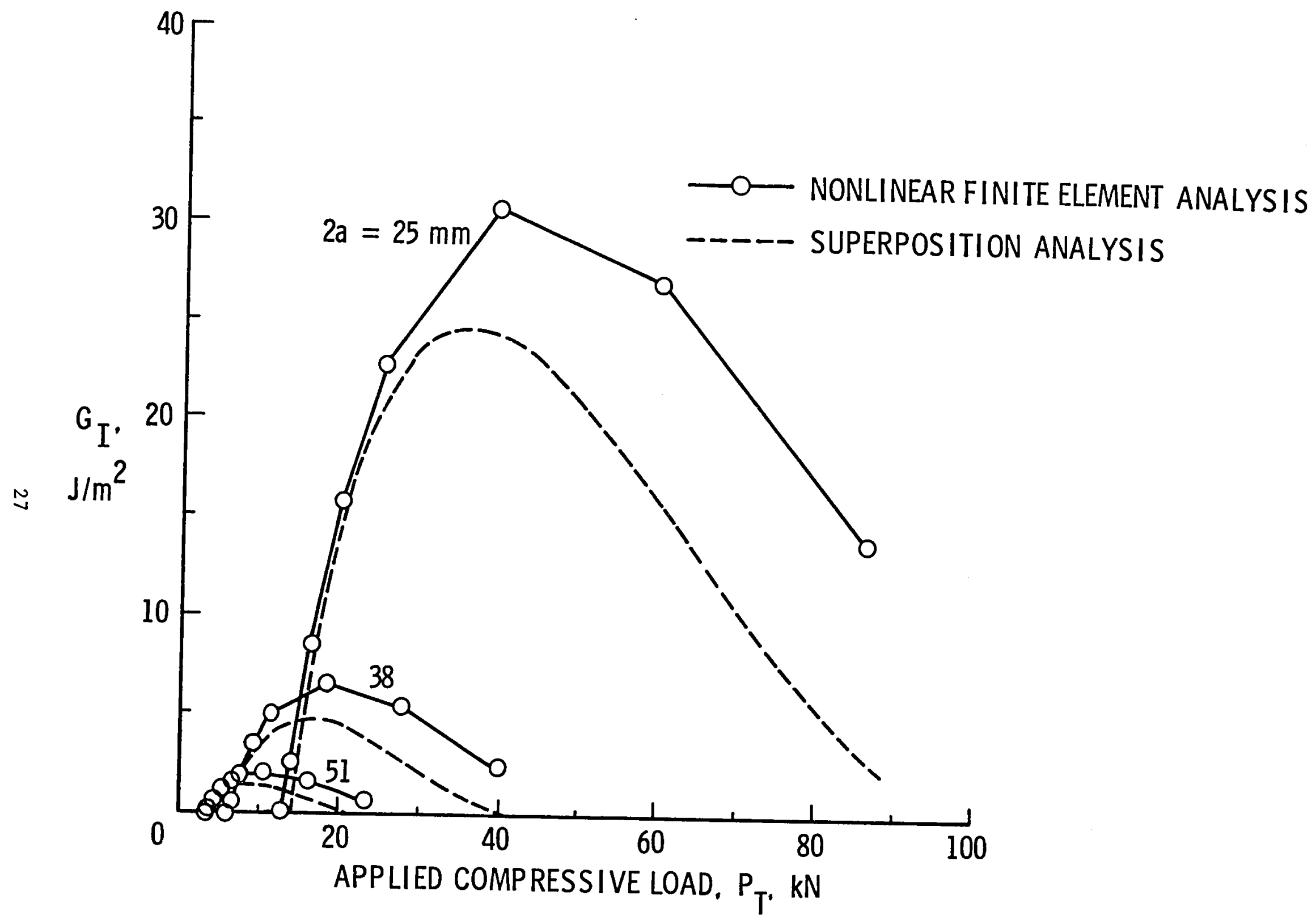
Fig. 6- Evaluation of approximate superposition analysis $\left(\left(P_{C}-P_{D}\right)\right.$ and $M$
from strength of materials analysis $)$. 


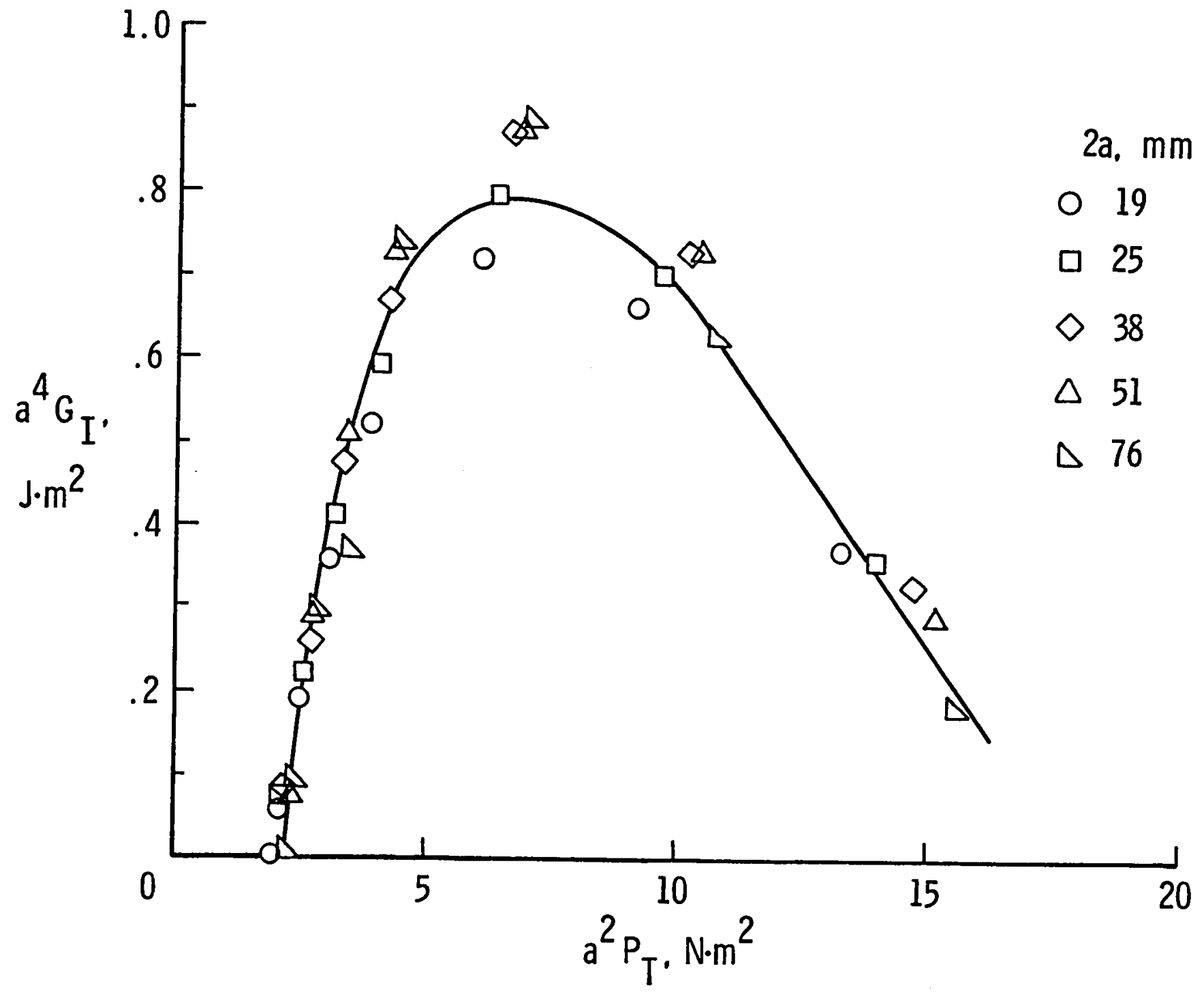

Fig. 7- Compaction of results from geometrically nonlinear analysis. (Curve is visual fit of data.) 


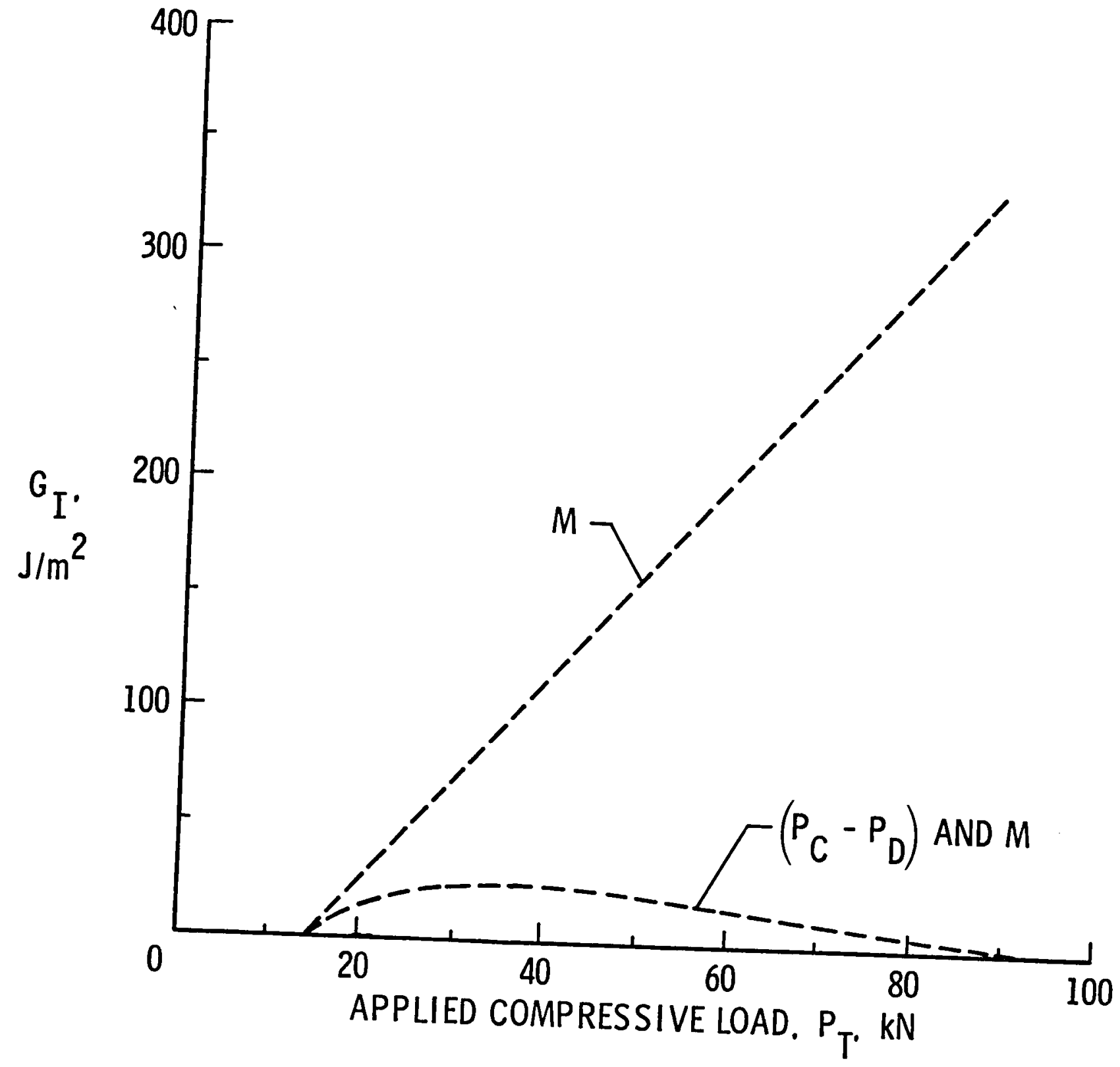

Fig. 8- Effect of $\left(P_{C}-P_{D}\right)$ and $M$ on $G_{I}(2 a=25$ m). 


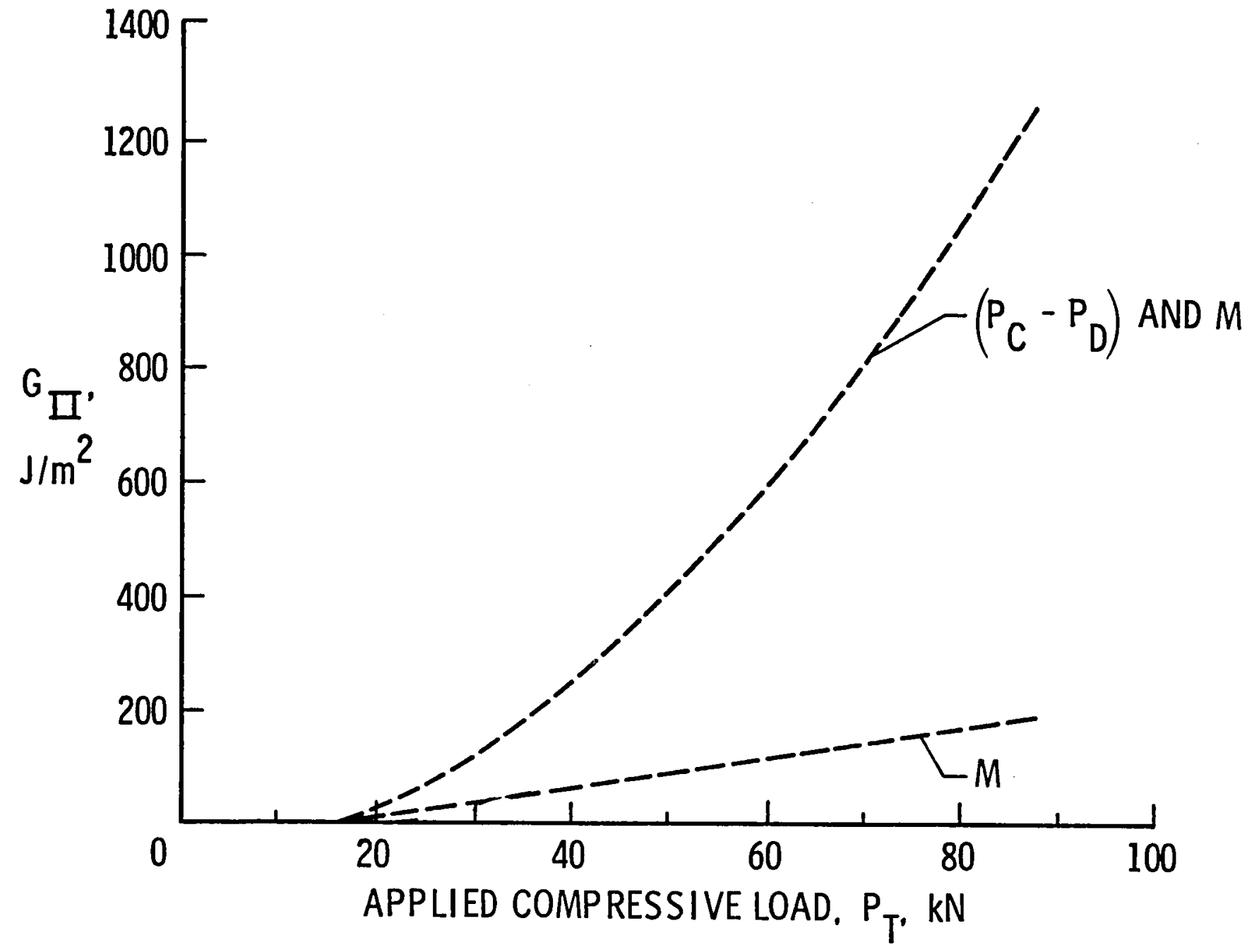

Fig. 9- Effect of $\left(P_{C}-P_{D}\right)$ and $M$ on $G_{I I}(2 a=25 \mathrm{~mm})$. 


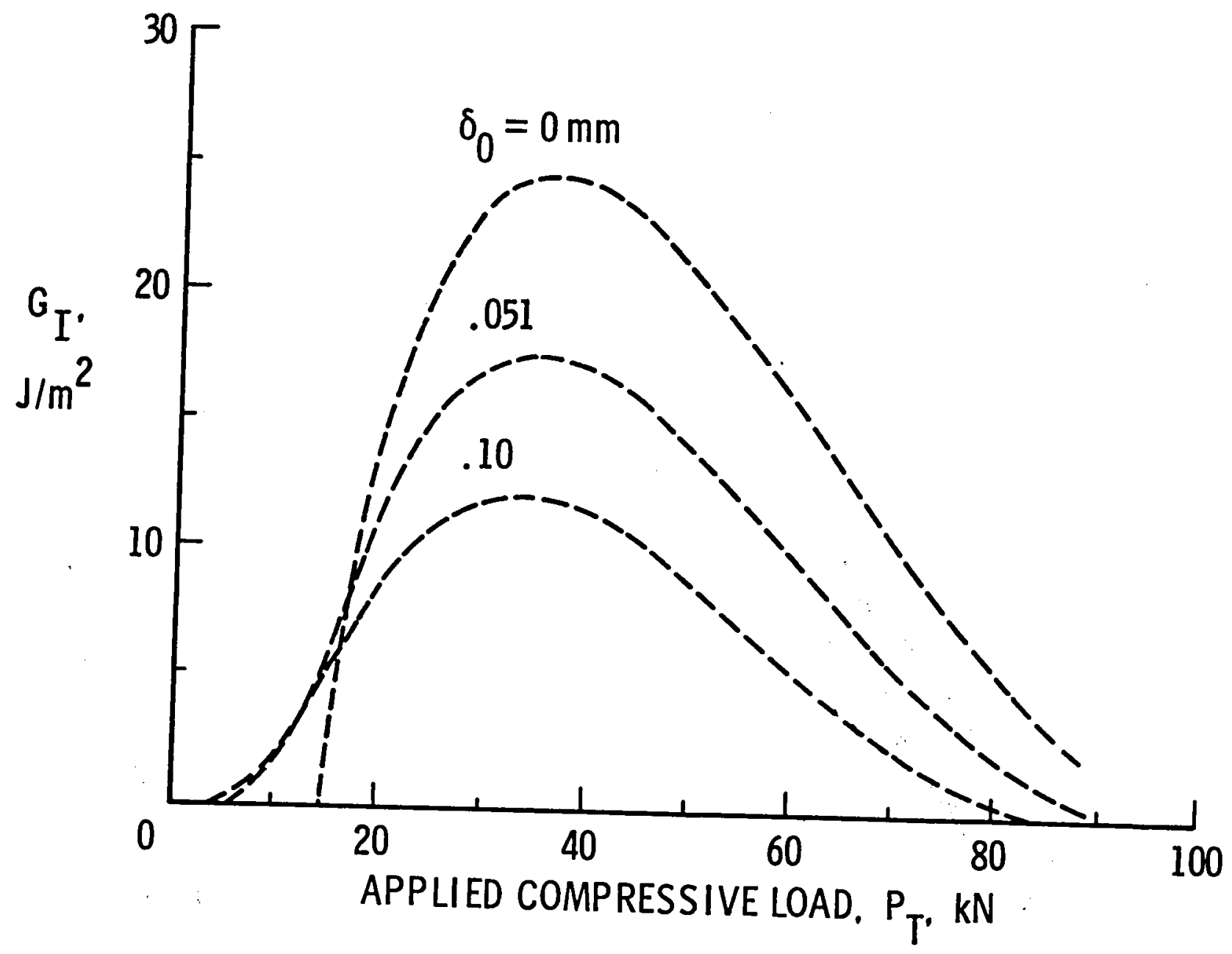

Fig. 10- Effect of initial imperfection $\delta_{0}$ on $G_{I} \quad(2 a=25 \mathrm{~mm})$. 


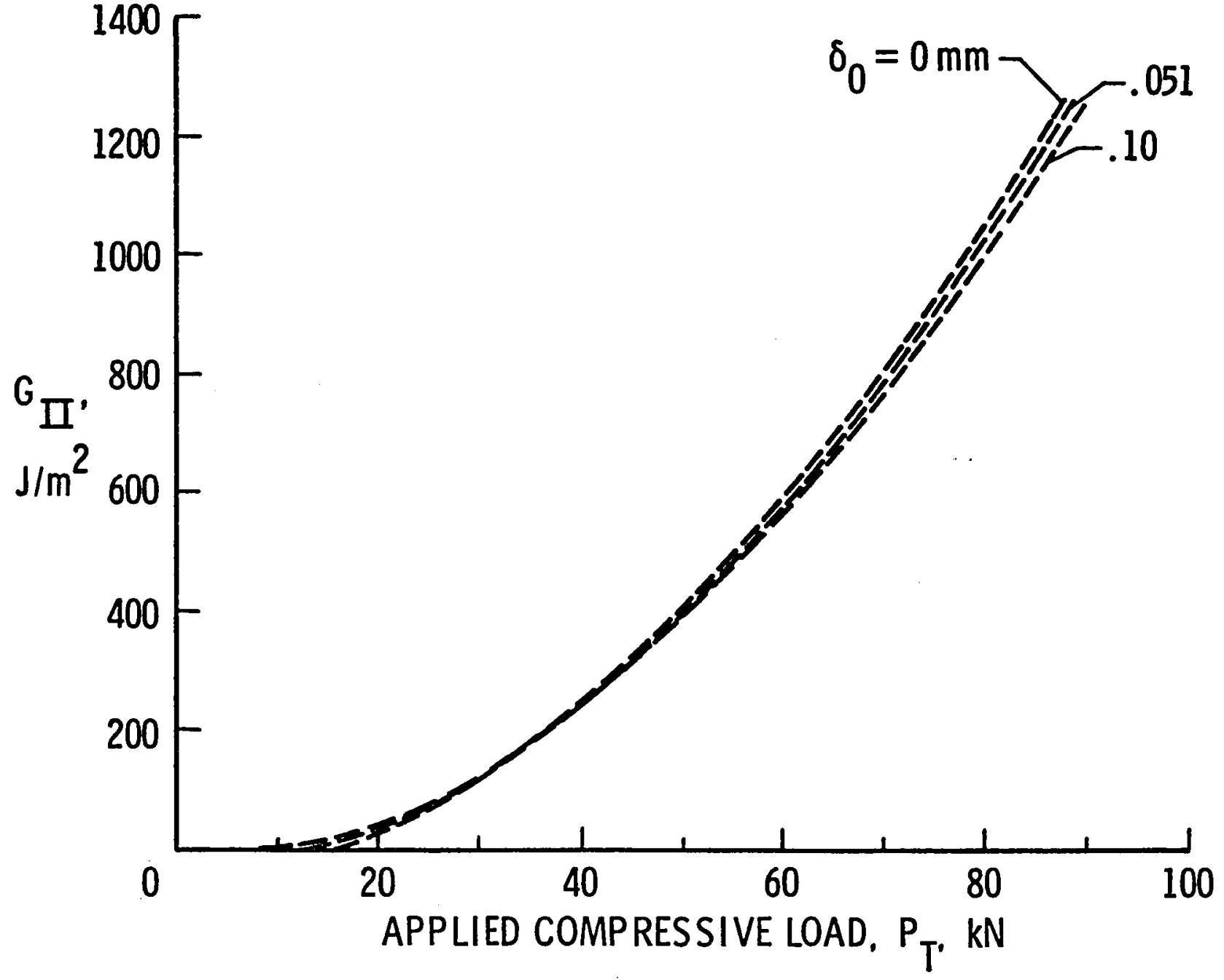

Fig. 11- Effect of initlal imperfection $\delta_{0}$ on $G_{I I}(2 a=25 \mathrm{~mm})$. 


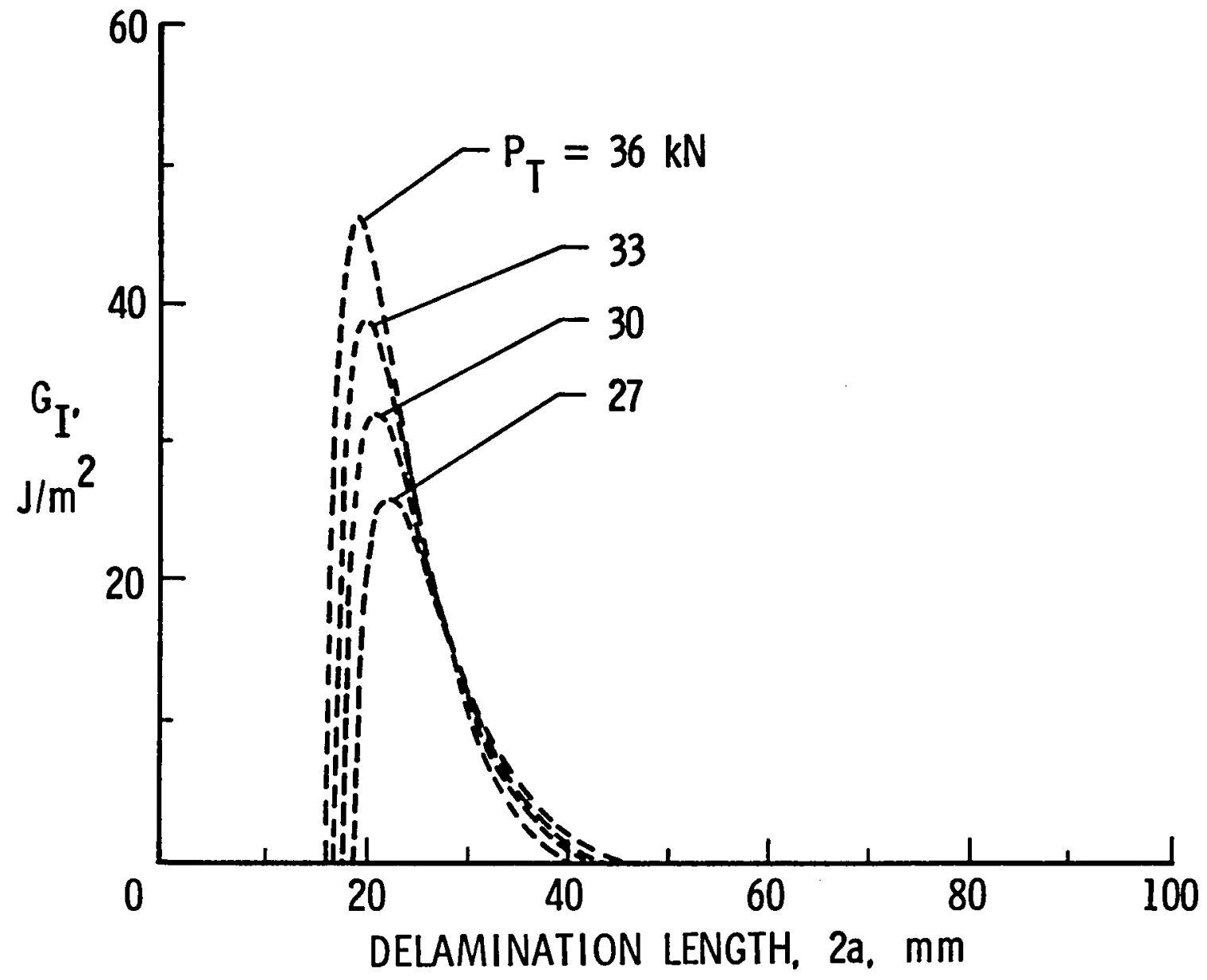

Fig. 12- Effect of delamination length on $G_{I}$. 


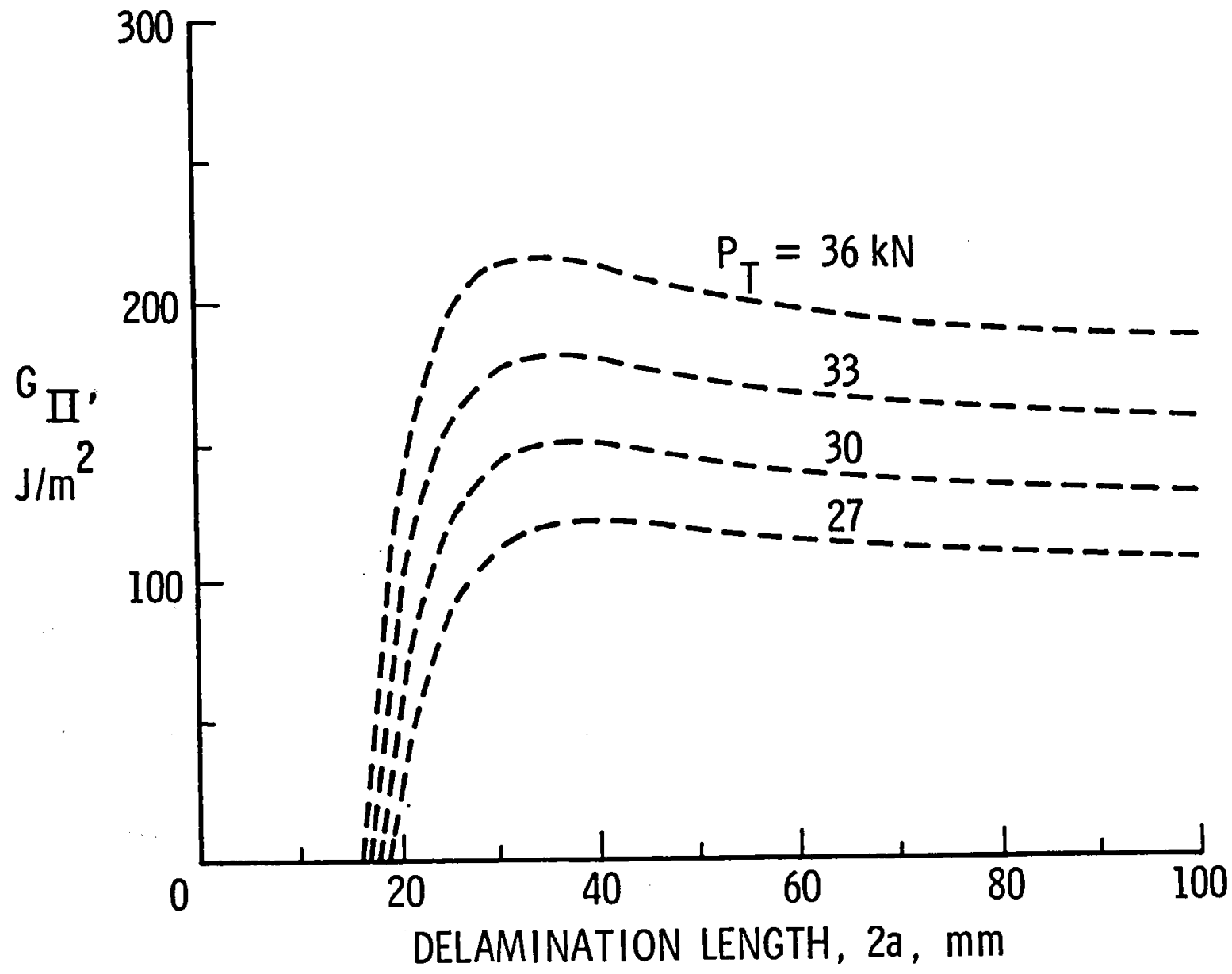

Fig. 13- Effect of delamination length on $G_{I I}$. 


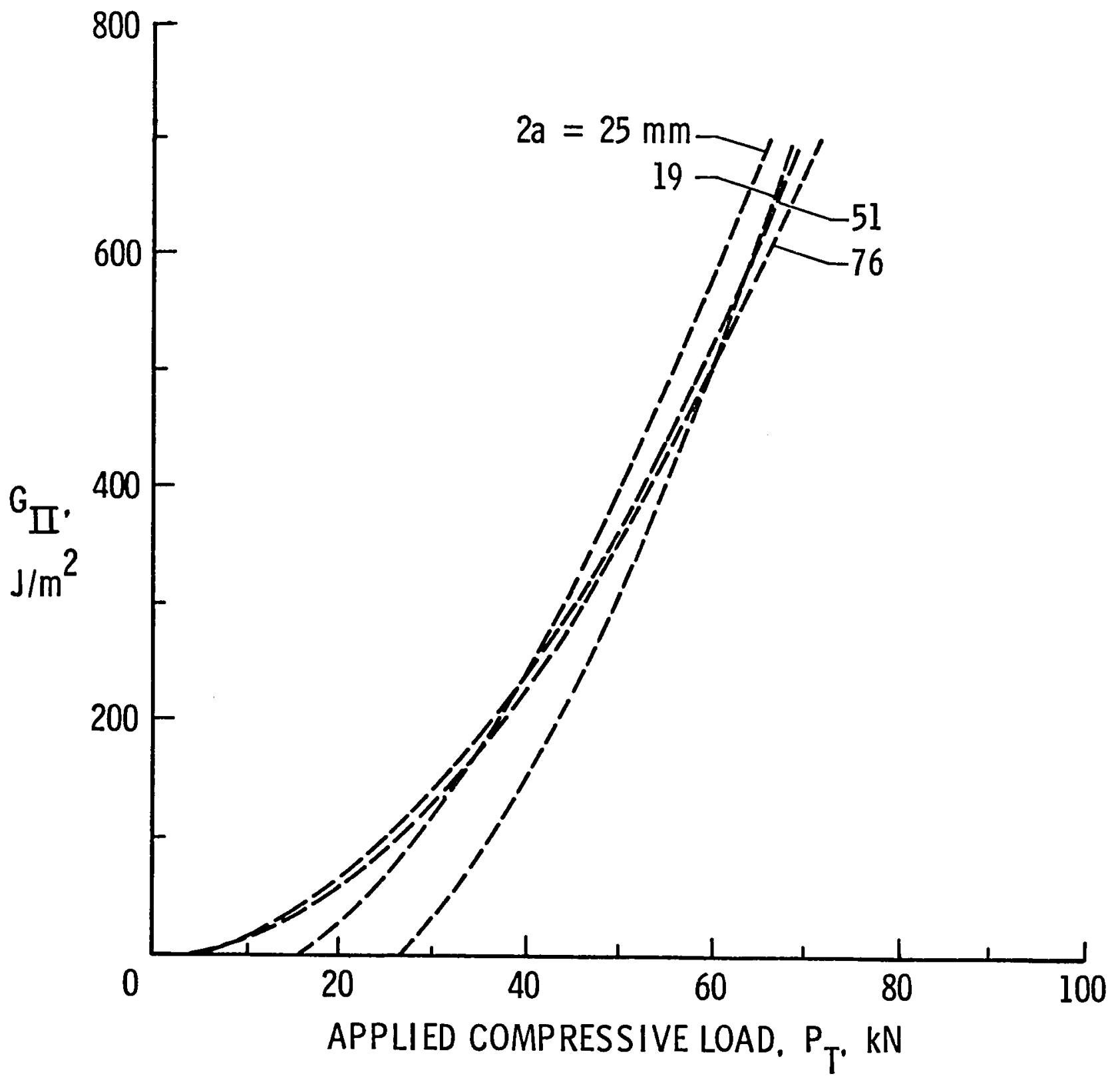

Fig. 14- Effect of applied compressive load on $G_{I I}(2 a=25 \mathrm{~mm})$. 


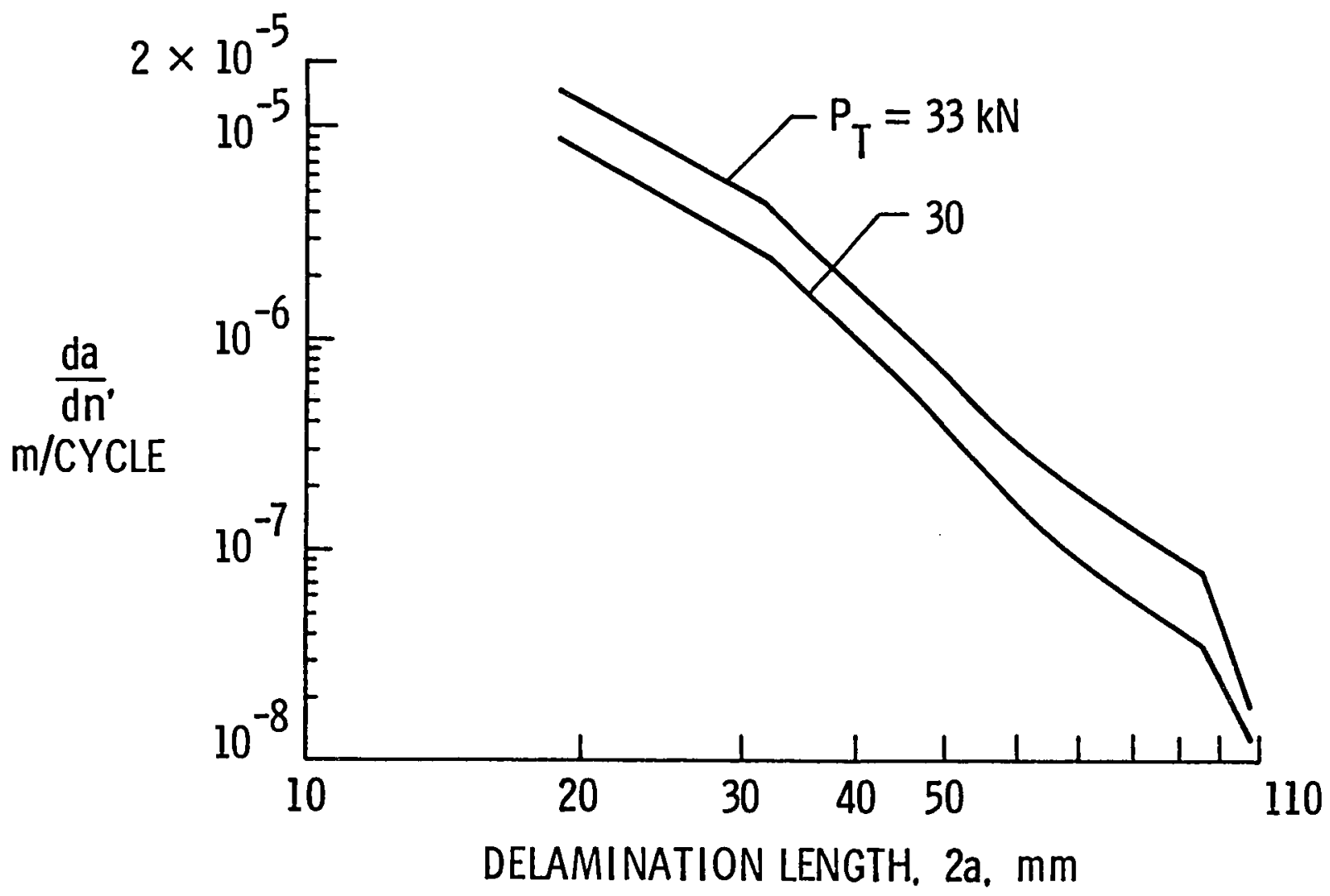

Fig. 15- Effect of delamination length and load on growth rate. 


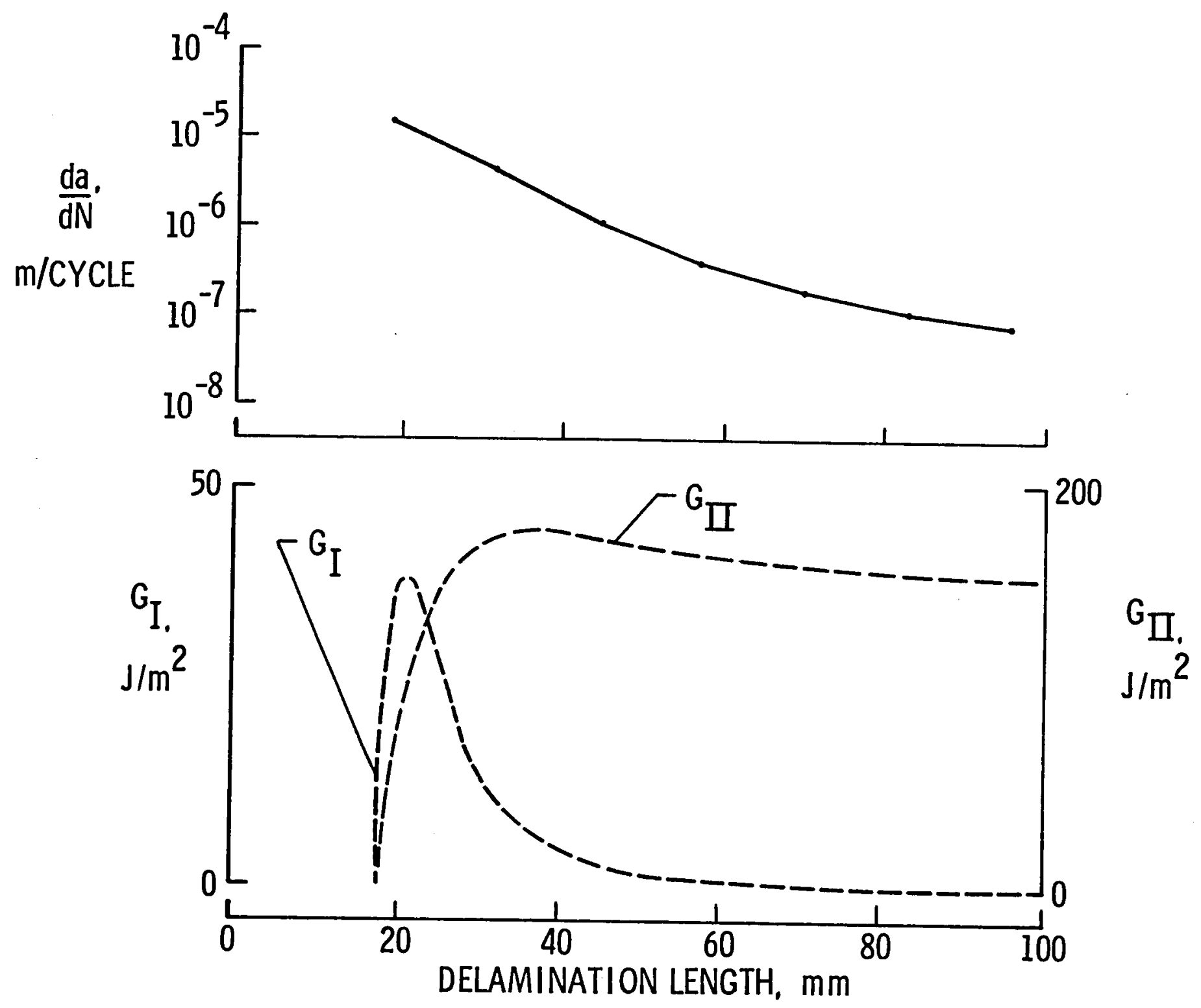
Fig. 16- Comparison of $\mathrm{G}_{\mathrm{I}}, \mathrm{G}_{\mathrm{II}}$, and delamination growth rate for maximum
fatigue load of $33 \mathrm{kN}$. 


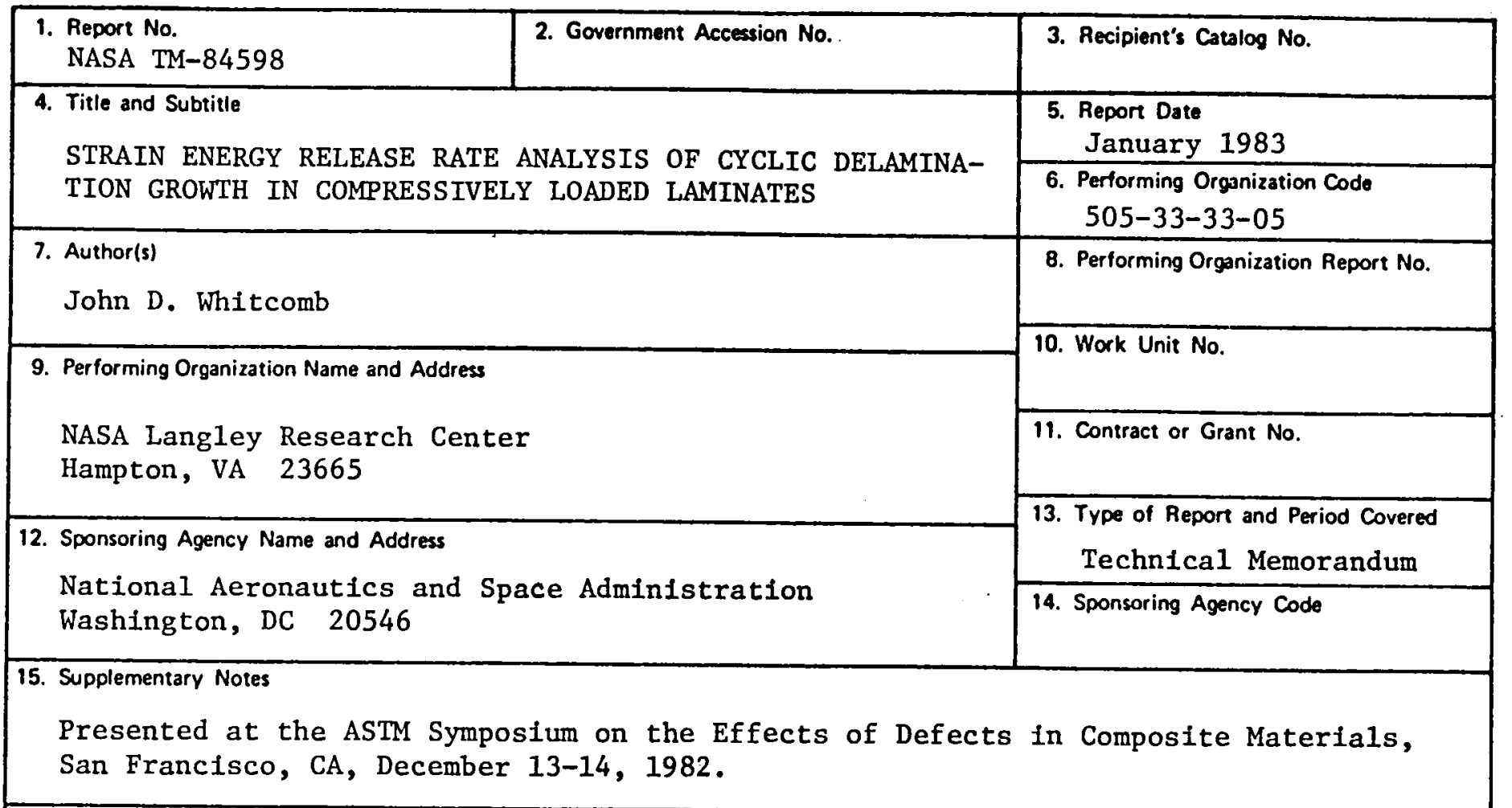

16. Abstract

Delamination growth in compressively loaded composite laminates was studied analytically and experimentally. The configuration used in the study was a laminate with an across-the-width delamination. An approximate superposition stress analysis was developed to quantify the effects of various geometric, material, and load parameters on mode $I$ and mode II strain energy release rates $G_{I}$ and $\mathrm{G}_{I I}$, respectively. Calculated values of $G_{I}$ and $G_{I I}$ were then compared with measured cyclic delamination growth rates to determine the relative importance of $G_{I}$ and $G_{I I}$. High growth rates were observed only when $G_{I}$ was large. However, slow growth was observed even when $G_{I}$ was negligibly small. This growth apparently was due to a large value of $\mathrm{G}_{\mathrm{II}}$.

17. Key Words (Suggested by Author(s))

Composite materials

Laminates

Delamination

Local buckling

Nonlinear stress analysis

Compression

19. Security Classif. (of this report) Unclassified
18. Distribution Statement

$$
\text { Unclassifled - Unlimited }
$$

Subject Category 24
20. Security Classif. (of this page) Unclassified
21. No. of Pages

38
22. Price

$\mathrm{AO} 3$ 
